\title{
Ortho-Substituent Effect on Fluorescence and Electroluminescence of Arylamino-Substituted Coumarin and Stilbene
}

\author{
Chao-Tsen Chen, ${ }^{*, \dagger}$ Chih-Long Chiang, ${ }^{\ddagger}$ Yu-Chung Lin, ${ }^{\dagger} \mathrm{Li}-\mathrm{H}$ sin Chan, ${ }^{\ddagger}$ \\ Chien-Huang Huang, ${ }^{\dagger}$ Zong-Wei Tsai, ${ }^{\ddagger}$ and Chin-Ti Chen ${ }^{*} \neq$
}

Department of Chemistry, National Taiwan University, Taipei, Taiwan 106, R.O.C., and Institute of Chemistry, Academia Sinica, Taipei, Taiwan 11529, R.O.C.

chenct@ntu.edu.tw; cchen@chem.sinica.edu.tw

Received February 17, 2003
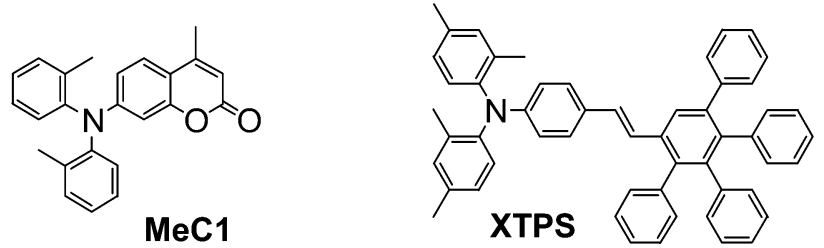

Newly synthesized arylamino-substituted coumarins and stilbenes show enhanced fluorescence emission (bluer and brighter) both in solution and in solid film. Pure blue efficient electroluminescence with $2.7 \%$ and $4.1 \%$ of external quantum efficiency can be achieved with MeC1 and XTPS, respectively.

Many fluorescent organic compounds exhibit high fluorescent quantum yields $\left(\Phi_{f}\right)$ in solution but suffer from "concentration quenching", showing little or no fluorescence at highly concentrated solution or in the solid state. ${ }^{1}$ The "concentration quenching" causes emission band broadening and a bathochromic shift. From a structural point of view, incorporation of bulky as well as nonplanar molecular moieties should prevent orderly molecular packing, and may alleviate the fluorescence quenching resulting from molecular interactions. ${ }^{2}$ Structural moieties, such as bulky tert-butyl, isopropyl, and tetraphenylsilyl, ${ }^{3}$ or sterically crowded tetraor pentaphenylphenyl polycycle,${ }^{4}$ provide satisfactory effects

\footnotetext{
Department of Chemistry, National Taiwan University.

$\doteqdot$ Institute of Chemistry, Academia Sinica

(1) Krasovitskii, B. M.; Bolotin, B. M. Organic Luminescent Materials; Vopian, V. G., Translator; VCH: Weinheim, Germany, 1988.

(2) Valeur, B. Molecular Fluorescence; Wiley-VCH: Weinheim, Germany, 2002.

(3) (a) Rademacher, A.; Märkle, S.; Langhals, H. Chem. Ber. 1982, 115, 2927. (b) Bohnen, A.; Koch, K.-H.; Lüttke, W.; Müllen, K. Angew. Chem., Int. Ed. Engl. 1990, 29, 525. (c) Geerts, Y.; Quante, H.; Platz, H.; Mahrt, R.; Hopmeier, M.; Böhm, A.; Müllen, K. J. Mater. Chem. 1998, 8, 2357.
}

on inhibiting molecular aggregation in the solid state. Molecules with a starburst or dendrimer shape show the effect as well. ${ }^{5}$ Nonplanar triarylamine structural moieties have been studied in depth, ${ }^{6}$ and have been found to be

(d) Chen, C. H.; Tang, C. W.; Shi, J.; Klubek, K. P. Thin Solid Films 2000, 363, 327. (e) Langhals, H.; Ismael, R.; Yürük, O. Tetrahedron 2000, 56, 5435. (f) Chen, C. H.; Tang, C. W. Appl. Phys. Lett. 2001, 79, 3711. (g) Chan, L.-H.; Yeh, H.-C.; Chen, C.-T. Adv. Mater. 2001, 13, 1637.

(4) (a) Gensch, T.; Hofkens, J.; Heirmann, A.; Tsuda, K.; Verheijen, W.; Vosch, T.; Christ, T.; Basché, T.; Müllen, K.; De Schryver, F. C. Angew. Chem., Int. Ed. 1999, 38, 3752. (b) Satayesh, S.; Grimsdale, A. C.; Weil, T.; Enkelmann, V.; Müllen, K.; Meghdadi, F.; List, E. J. W.; Leising, G. J. Am. Chem. Soc. 2001, 123, 946. (c) Pogantsch, A.; Wenzl, F. P.; List, E. J. W.; Leising, G.; Grimsdale, A. C.; Müllen, K. Adv. Mater. 2002, 14, 1061.

(5) (a) Bettenhausen, J.; Strohriegl, P. Adv. Mater. 1996, 8, 507. (b) Katsuma, K.; Shirota, Y. Adv. Mater. 1998, 10, 223. (c) Halim, M.; Pillow, J. N. G.; Samuel, I. D. W.; Burn, P. L. Adv. Mater. 1999, 11, 371. (d) Lupon, J. M.; Hemingway, L. R.; Samuel, I. D. W.; Burn, P. L. J. Mater. Chem. 2000, 10, 867. (e) Freeman, A. W.; Koene, S. C.; Malenfant, P. R. L.; Thompson, M. E.; Fréchet, J. M. J. J. Am. Chem. Soc. 2000, 122, 12385. (f) Wang, S.; Oldham, W. J., Jr.; Hudack, R. A.; Bazan, G. C. J. Am. Chem. Soc. 2000, 122, 5695. (g) Yeh, H.-C.; Lee, R.-H.; Chan, L.-H.; Lin, T.-Y. J.; Chen, C.-T.; Balasubramaniam, B.; Tao, Y.-T. Chem. Mater. 2001, 13, 2788. (h) Ostrowski, J. C.; Robinson, M. R.; Heeger, A. J.; Bazan, G. C. Chem. Commun 2002, 784. 
effective in generating molecular glass materials. However, besides preventing molecules from crystallization, none of these structural moieties or shapes per se have a direct control on the photophysical properties of the fluorophores. In this Letter, we take one step further to show a molecular strategy, namely the ortho-substitutent effect of arylamine, which can effectively enhance fluorescence in the solid state while preserving the intrinsic $\Phi_{f}$ in solution with a concomitant hypsochromic emission shift. The structural strategy is successfully applied to two kinds of fluorophores, coumarin and stilbene. In addition, bright and efficient blue electroluminescence (EL) observed for nondoping organic lightemitting diodes (OLEDs) fabricated from structure-tailored coumarin and stilbene derivatives further strengthens the validity of the approach.

Coumarin 1 (7-diethylamino-4-methylcoumarin, C1) is an appropriate fluorophore to serve as the molecular platform to illustrate the strategy owing to its near unit blue fluorescence efficiency in solution, but weak fluorescence in the solid state. ${ }^{7}$ Accordingly, diaryl appended $\mathbf{C 1}$ derivatives (denoted by $\mathbf{P h C 1}, \mathbf{M e C 1}$, and $\mathbf{C l C 1}$ ) are synthesized (Scheme 1). Although Pd-catalyzed aromatic amination

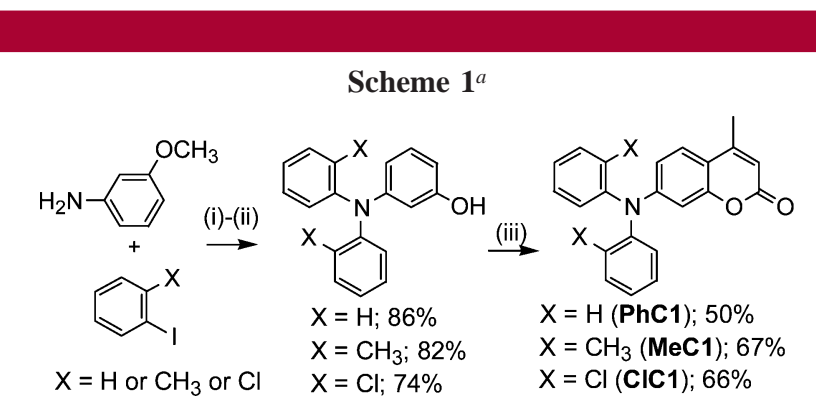

${ }^{a}$ Reagents and conditions: (i) 1,2-dichlorobenzene, copper bronze, 18-crown- $6, \mathrm{~K}_{2} \mathrm{CO}_{3}$, reflux, 4 days, $85 \%(\mathrm{X}=\mathrm{H}), 77 \%$ $\left(\mathrm{X}=\mathrm{CH}_{3}\right), 30 \%(\mathrm{X}=\mathrm{Cl})$; (ii) $\mathrm{BBr}_{3}, \mathrm{CH}_{2} \mathrm{Cl}_{2},-78{ }^{\circ} \mathrm{C} \rightarrow \mathrm{rt}, 8 \mathrm{~h}$; (iii) acetoacetate, $70 \% \mathrm{H}_{2} \mathrm{SO}_{4}(\mathrm{aq})$.

reactions ${ }^{8}$ are commonly employed in the synthesis of triarylamines, ${ }^{9}$ they failed to give 3-bisarylamino anisole, but only a monosubstituted compound isolated even after a prolonged reaction time or by the addition of an excess of chelating or nonchelating phosphine ligands. The aryl groups were thus introduced to the amino group via the Ullmann reaction ${ }^{10}$ starting with 3-methoxyaniline followed by the

(6) For reviews, see: (a) Shirota, Y. J. Mater. Chem. 2000, 10, 1. (b) Thelakkat, M. Macromol. Mater. Chem. Eng. 2002, 287, 442

(7) Jones, G., II; Jackson, W. R.; Choi, C.-Y.; Bergmark, W. R. J. Phys. Chem. 1985, 89, 294.

(8) (a) Wolfe, J. P.; Wagaw, S.; Marcoux, J.-F.; Buchwald, S. L. Acc. Chem. Res. 1998, 31, 805. (b) Hartwig, J. F. Angew. Chem., Int. Ed. 1998, 37, 2046.

(9) For recent examples, see: (a) Yamamoto, T.; Nishiyama, M.; Koie, Y. Tetrahedron Lett. 1998, 39, 2367. (b) Goodson, F. E.; Hauck, S. I.; Hartwig, J. F. J. Am. Chem. Soc. 1999, 121, 7527. (c) Watanabe, M.; Nishiyama, M.; Yamamoto, T.; Koie, Y. Tetrahedron Lett. 2000, 41, 481. (d) Harris, M. C.; Buchwald, S. L. J. Org. Chem. 2000, 65, 5327. (e) Watanabe, M.; Yamamoto, T.; Nishiyama, M. Chem. Commun. 2000, 133.

(10) (a) Goodbrand, H. B.; Hu, N.-X. J. Org. Chem. 1999, 64, 670. (b) Bacon, R. G. R.; Hill, H. A. O. Chem. Rev. 1965, 19, 95. (c) Bushby, R. J.; McGill, D. R.; Ng, K. M.; Taylor, N. J. Mater. Chem. 1997, 7, 2343. (d) Gauthier, S.; Frechet, J. M. J.; Synthesis, 1987, 383. treatment of $\mathrm{BBr}_{3}$ to give the corresponding phenols, which were further condensed with ethyl acetoacetate under a Pechmann condition to yield the aryl-substituted coumarins. Low reaction yields were observed if Lewis acids such as zinc chloride were used as catalysts for the condensation.

PhC1 displays relatively low fluorescence yield $\left(\Phi_{f}=\right.$ $48 \%$ ) and a large bathochromic shift relative to C1 in emission wavelength, indicating there is partial conjugation between the chromen-2-one and the diphenylamino group. The solid-state fluorescence intensity of PhC1 was improved relatively (Figure 1), although fluorescence quantum yield

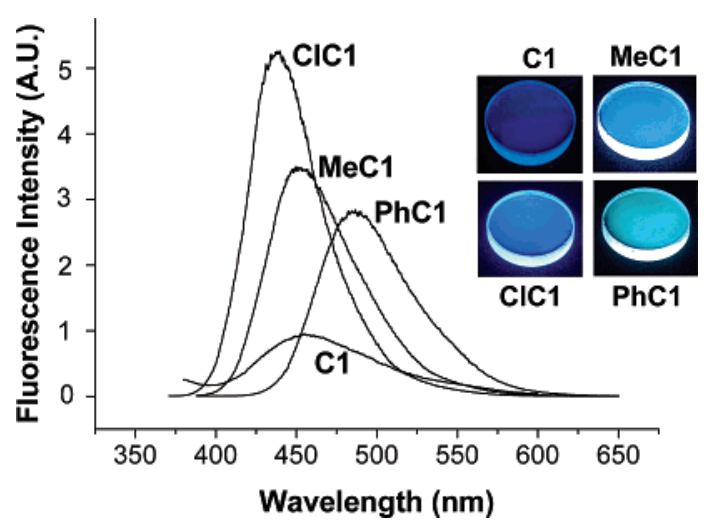

Figure 1. Left: Fluorescence emission spectra of Coumarin 1 (C1), ClC1, MeC1, and PhC1 as solid films on quartz. Right: Color photographs of the same solid films under UV irradiation $(365 \mathrm{~nm})$ qualitatively revealing relative fluorescence intensity and varied blue hue.

in the solid state awaited for measurement. Nevertheless, the fluorescence emission maximum $\left(\lambda_{\max }^{\mathrm{em}}\right)$ of the solid film appeared at $474 \mathrm{~nm}$ corresponding to the greenish blue hue. The color purity is thus not appropriate for the application in OLED, strictly requiring good blue-color purity. In the cases of MeC1 and $\mathbf{C l C 1}$, the ortho substituents (i.e., methyl and chloro groups) of phenyl groups augment the nonplanarity of the triarylamino center to prevent crystallization, as well as reduce the extent of conjugation between the chromen-2-one and the diarylamino group.

The structural features are reflected in the photospectroscopic and electrochemical data. The fluorescence quantum yields of $\mathbf{M e C 1}$ and $\mathbf{C l C 1}$ are $77 \%$ and $86 \%$, respectively, and emission wavelengths are much shorter than that of PhC1 (Table 1, Figure 1), either in solutions or in solid films. The gradually increasing oxidation potentials, implying wider energy gaps between HOMO and LUMO, are observed at 0.56, 0.64, and 0.88 V in the order of PhC1, MeC1, and CIC1 (Table 1) consistent with blue-shifted wavelengths in absorption and fluorescence spectra. The LUMO energy level of the compounds remained mostly the same due to the very similar reduction potential. This is understandable because of the reduction site, assuming the carbonyl of chromenone has the same chemical structure in three molecules. Besides the energy gap law, the rather pronounced fluorescence 
Table 1. Spectral, Thermal, and Electrochemical Data of Coumarin and Stilbene Compounds

\begin{tabular}{|c|c|c|c|c|c|c|c|c|}
\hline & \multirow{2}{*}{$\begin{array}{c}\Phi_{f} \\
(\%)^{a}\end{array}$} & \multirow{2}{*}{$\begin{array}{c}\lambda_{\max }{ }^{\text {abs }} \\
(\mathrm{nm})^{\mathrm{b}}\end{array}$} & \multicolumn{2}{|c|}{$\lambda_{\max }{ }^{\mathrm{em}}(\mathrm{nm})$} & \multirow{2}{*}{$\begin{array}{c}\mathrm{T}_{\mathrm{g}} \\
\left({ }^{\circ} \mathrm{C}\right)\end{array}$} & \multirow{2}{*}{$\begin{array}{c}\mathrm{T}_{\mathrm{m}} \\
\left({ }^{\circ} \mathrm{C}\right)\end{array}$} & \multirow{2}{*}{$\begin{array}{c}\mathrm{T}_{\mathrm{d}} \\
\left({ }^{\circ} \mathrm{C}\right)\end{array}$} & \multirow{2}{*}{$\begin{array}{l}\text { Eoxd } \\
(V)^{g}\end{array}$} \\
\hline & & & solutionb & solid & & & & \\
\hline 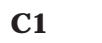 & 99 & 365 & 416 & $456^{c}$ & e & 71 & $f$ & 1 \\
\hline PhC & 48 & 36 & 464 & $474^{c}$ & 42 & 171 & 253 & 0.5 \\
\hline $\mathrm{MeC}$ & 77 & 362 & 443 & $451^{c}$ & 56 & 160 & 257 & 0.6 \\
\hline CIC & 86 & 347 & 411 & $435^{c}$ & 61 & 185 & 285 & 0.8 \\
\hline ATPS & 36 & 382 & 502 & $492^{d}$ & 110 & 210 & 348 & 0.2 \\
\hline TPS & 56 & 380 & 474 & $471^{d}$ & 114 & 235 & 354 & 0.3 \\
\hline XTPS & 54 & 370 & 462 & $465^{d}$ & 120 & e & 370 & 0.3 \\
\hline
\end{tabular}

${ }^{a}$ Coumarin $1\left(\Phi_{f}=99 \% \text { in ethyl acetate }\right)^{7}$ was used as the standard for the fluorescence quantum yield determination. ${ }^{b}$ Samples were dissolved in ethyl acetate when spectra were recorded. ${ }^{c}$ Solid films were prepared by thermal deposition under vacuum. ${ }^{d}$ Solid films were prepared by spincasting from solution and then vacuum dried. ${ }^{e}$ Not detectable. ${ }^{f}$ Not measured. ${ }^{g}$ Sample was dissolved in deoxygened dichloromethane with tetrabutylammonium hexfluorophosphate (PhC1, MeC1, and CIC1) or perchlorate (ATPS, TTPS, and XTPS) as the electrolyte. A platinum working electrode and a saturated $\mathrm{Ag} / \mathrm{AgNO}_{3}$ reference electrode were used. Ferrocene was used for potential calibration (all reported potentials are referenced to ferrocene/ferrocenium)

enhancements for $\mathbf{M e C 1}$ and $\mathbf{C l C 1}$ in solutions compared to $\mathbf{P h C 1}$ could be attributed to the increase of the potential energy of nonradiative twisted intramolecular charge transfer (TICT) by tuning the electronic properties of aryl amino groups. ${ }^{11}$

Three coumarin derivatives reported here sharing the same triarylamino structural features do exhibit improved amorphous properties relative to $\mathbf{C} \mathbf{1}$. The crystallinic $\mathbf{C} \mathbf{1}$ shows a melting temperature $\left(T_{\mathrm{m}}\right)$ around $71{ }^{\circ} \mathrm{C}$. In contrast, $T_{\mathrm{m}}$ of PhC1 is detected at $171{ }^{\circ} \mathrm{C}$ by DSC (differential scanning calorimetry) examination in the first heating scan, and neither a melting nor a crystallization signal, rather a steplike endothermic signal corresponding to the glass transition temperature $\left(T_{\mathrm{g}}\right)$, is observed at $42{ }^{\circ} \mathrm{C}$ in the second and subsequent heating scans. Similar to PhC1, $T_{\mathrm{g}}$ values are detected for MeC1 and $\mathbf{C I C 1}$ at 56 and $61{ }^{\circ} \mathrm{C}$, respectively. The results indicate that $\mathbf{P h C 1}, \mathbf{M e C 1}$, and $\mathbf{C l C 1}$ possess suppressed intermolecular interactions in the solid state. The thermal properties mirror the solid-state fluorescence studies of these derivatives: the crystallinic $\mathbf{C 1}$ showing the largest red-shift difference between solutions and solid states (Table 1), owing to the severe molecular interactions, and CIC1 exhibiting the bluest and brightest solid-state fluorescence emission (Figure 1).

To explore the generality of the "ortho-substituent effect" shown for C1, a new type of stilbene, ATPS, TTPS, and XTPS, is synthesized (Scheme 2). The Horner-WadsworthEmmons reaction was used for the formation of the $\mathrm{C}-\mathrm{C}$ double bond to connect triarylamine and tetraphenylbenzene. The required diethyl tetraphenylphenylphosphonate was elaborately prepared in a stepwise manner by the DielsAlder cycloaddition of propiolic acid and tetraphenylcyclo-

(11) (a) Rettig, W. Angew. Chem., Int. Ed. Engl. 1986, 25, 971. (b) Rettig, W.; Vogel, M.; Drexhage, K. H.; Sens, R. Chem. Phys. Lett. 1988, 147, 452 .

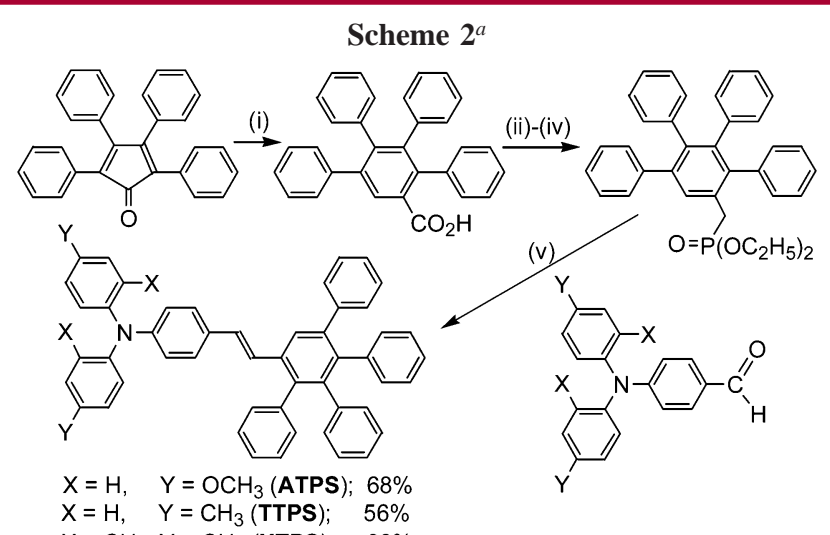

$X=\mathrm{CH}_{3}, \mathrm{Y}=\mathrm{CH}_{3}$ (XTPS); $68 \%$

${ }^{a}$ Reagents and conditions: (i) propiolic acid, bromobenzene, 160 ${ }^{\circ} \mathrm{C}, 12 \mathrm{~h}, 81 \%$; (ii) $\mathrm{LiAlH}_{4} / \mathrm{THF}, 0 \rightarrow 80{ }^{\circ} \mathrm{C}, 7 \mathrm{~h}, 97 \%$; (iii) $\mathrm{CCl}_{4} /$ $\mathrm{PPh}_{3}$, toluene, $120^{\circ} \mathrm{C}, 6 \mathrm{~h}, 60 \%$; (iv) $\mathrm{P}\left(\mathrm{OC}_{2} \mathrm{H}_{5}\right)_{3}, 160{ }^{\circ} \mathrm{C}, 4 \mathrm{~h}, 90 \%$; (v) $\mathrm{NaH} / \mathrm{THF}$.

pentadienone, followed by functional group transformations to yield the corresponding phosphonate ester.

The combination of sterically crowded tetraphenylphenyl moieties and the ortho-substituted arylamine in molecular structures should provide us with noncrystallinic stilbene derivatives with strong fluorescence emission, as well as good blue-color purity. In fact, XTPS is the only fluorophore in this report showing $T_{\mathrm{g}}$ in the absence of $T_{\mathrm{m}}$ on DSC thermograms. Their thermal, spectral, and electrochemical data are summarized in Table 1 for comparisons. As we expected, the XTPS bearing the ortho-substituted arylamino moiety displays the best fluorescence properties: relatively high $\Phi_{f}(54 \%)$ and a good blue-color hue either in solution $\left(\lambda_{\max }{ }^{\mathrm{em}} 462 \mathrm{~nm}\right)$ or in the solid state $\left(\lambda_{\max }{ }^{\mathrm{em}} 465 \mathrm{~nm}\right)$. TTPS exhibits a comparable fluorescence quantum yield with XTPS, ${ }^{12}$ but its emission wavelengths $\left(\lambda_{\max }{ }^{\mathrm{em}} 474 \mathrm{~nm}\right.$ in solution and $471 \mathrm{~nm}$ in solid film) are somewhat deviated from the blue hue. Similar to $\mathbf{P h C l}$, MeC1, and ClC1, increasing oxidation potentials are parallel to the blue-shifting wavelength of absorption and emission spectra (Table 1) in the order ATPS, TTPS, and XTPS. Here, we see the orthosubstituent effect on both blue-shifting fluorescence and inhibiting crystallization of molecules.

Good OLEDs primarily require materials with efficient emission in the solid state and are ideal for the demonstration of ortho-substituent effect on blue fluorophores. Accordingly, two nondoping OLEDs, in the configuration of ITO/NPB (40 nm)/MeC1 (30 nm)/TPBI (40 nm)/Mg $: \mathrm{Ag}_{1}$ and ITO/ XTPS $(60 \mathrm{~nm}) / \mathrm{TPBI}(40 \mathrm{~nm}) / \mathrm{Mg}_{9}: \mathrm{Ag}_{1}$ are fabricated. ${ }^{13}$ Both devices show one blue EL band centered at 458 and 462 $\mathrm{nm}$, respectively (Figure 2). These wavelengths are rather close to those of PL observed for each blue fluorophore in the solid state (Table 1), indicative of the fluorophore origin of the EL.

(12) Nearly the same $\Phi_{f}$ values of XTPS and TTPS are not unexpected Arylamino-substituted stilbene fluorophores bearing sterically hindered ortho substituents have a higher chance of going through trans-cis isomerization at the photoexcited state and hence exhibit weaker fluorescence intensity than those without an ortho substituent. Yang, J.-S.; Chiou, S.-Y.; Liau, K.-L. J. Am. Chem. Soc. 2002, 124, 2518. 


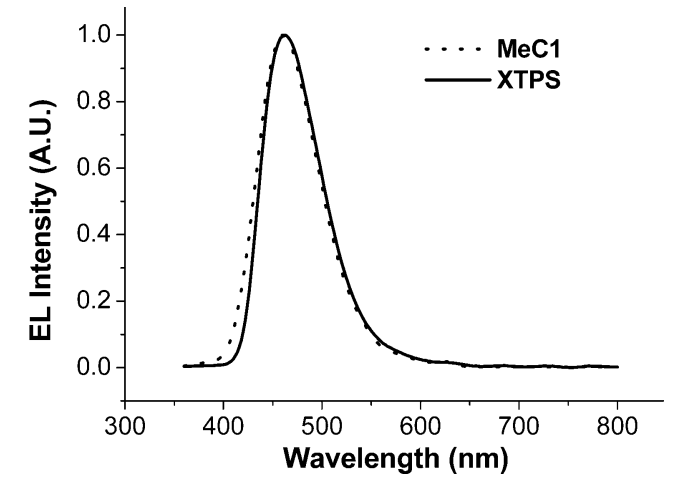

Figure 2. Electroluminescence spectra of OLEDs containing MeC1 (dotted line) and XTPS (solid line).

The MeC1-based device shows the maximum luminance around $3000 \mathrm{~cd} / \mathrm{m}^{2}$ and $2.7 \%$ external quantum efficiency (equivalent to $3.2 \mathrm{~cd} / \mathrm{A}$ or $1.1 \mathrm{~lm} / \mathrm{W}$ ) (Figure 3 ). The XTPS-

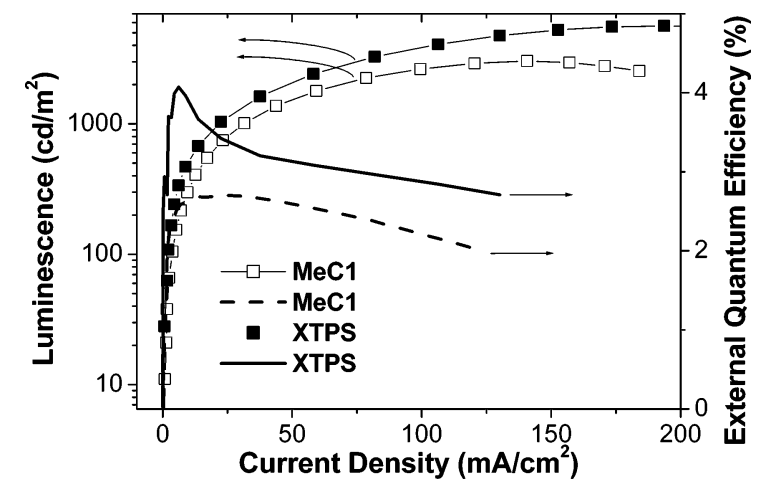

Figure 3. Electroluminescence intensity and external quantum efficiency of OLEDs containing MeC1 (dashed line and open symbol) and XTPS (solid line and solid symbol).

based device outperforms the MeC1-based one, displaying luminance as high as $5650 \mathrm{~cd} / \mathrm{cm}^{2}$, and maximum external quantum efficiency of $4.1 \%$ (equivalent to $5.5 \mathrm{~cd} / \mathrm{A}$ or 2.9 $\mathrm{lm} / \mathrm{W})^{14}$ at a low current density of $6 \mathrm{~mA} / \mathrm{cm}^{2}$ and a driving voltage of $6 \mathrm{~V}$.

Nevertheless, at a current density of $20 \mathrm{~mA} / \mathrm{cm}^{2}$ or lower, intense blue EL values as strong as $640 \mathrm{~cd} / \mathrm{m}^{2}$ (MeC1-based device) and $940 \mathrm{~cd} / \mathrm{m}^{2}$ (XTPS-based device) are observed for each device (Figure 3), which are practical for display application. To our knowledge, either of these blue emissions is one of the brightest among known blue OLEDs at a comparable range of low current density. ${ }^{13,15}$

In summary, we have successfully demonstrated that the ortho-substituted arylamino donor is an effectively structural tailor for blue-shifting fluorescence wavelength and for enhancing the fluorescent intensity of blue fluorophores either in solution or in the solid state (herein illustrated by two classes of compounds: Coumarin 1 and stilbene). Efficient and bright blue OLEDs, fabricated with XTPS or MeC1 blue light-emitting materials, also justify our structural approach.

Acknowledgment. We thank the National Science Council, the Academia Sinica, and the Ministry of Education of Taiwan for financial support. The assistance from Prof. YuTai Tao in the fabrication and measurement of the OLED devices is also acknowledged.

Supporting Information Available: Structural characterization of new coumarin and stilbene compounds; EL characterizations of MeC1 and XTPS-based OLEDs. This material is available free of charge via the Internet at http://pubs.acs.org.

\section{OL034268H}

(13) TPBI here denotes $2,2^{\prime}, 2^{\prime \prime}$-(1,3,5-phenylene)tris(1-phenyl-1 $H$-benzimidazole) and NPB is 1,4-bis(1-naphylphenylamino)biphenyl. ITO is an indium-tin oxide-coated glass. The fabrication and characterization of the devices follow a similar procedure to that reported by Chan et al.: Chan, L.-H.; Lee, R.-H.; Hsieh, C.-F.; Yeh, H.-C.; Chen, C.-T. J. Am. Chem. Soc. 2002, 124, 6469.

(14) At first glance, the very high $4.1 \%$ external quantum efficiency of the XTPS-based device seems unreasonable, considering the moderate $\Phi_{f}$ (54\%) of XTPS. However, recent reports indicate that the light out-coupling factor $\left(\eta_{\text {coupling }}\right.$ ) of OLEDs needs reevaluation. Underestimation of $\eta_{\text {coupling }}$ is possibly as high as 2-fold in previous estimations. (a) Chen, H. Y.; Lam, W. Y.; Luo, J. D.; Ho, Y. L.; Tang, B. Z.; Zhu, D. B. Appl. Phys. Lett. 2002, 81, 574. (b) Patel, N. K.; Cina, S.; Burroughes, J. H. IEEE J. Sel. Top. Quantum Electron. 2002, 8, 346.

(15) (a) Li, Y.; Fung, M. K.; Xie, Z.; Lee, S.-T.; Hung, L.-S.; Shi, J. Adv. Mater. 2002, 14, 1317. (b) Shih, H.-T.; Lin, C.-H.; Shih, H.-H.; Cheng, C.-H. Adv. Mater. 2002, 14, 1409. (c) Kim, Y.-H.; Shin, D.-C.; Kim, S.H.; Ko, C.-H.; Yu, H.-S.; Chae, Y.-S.; Kwon, S.-K. Adv. Mater. 2002, 14, 1690 . 